\title{
Looking at Resource Sharing Costs
}

Originally published:

Lars Leon, Nancy Kress, (2012),"Looking at resource sharing costs", Interlending \& Document Supply, Vol. 40 Iss: 2 pp. 81 - 87

Permanent link to this document http://dx.doi.org/10.1108/02641611211239542

Lars Leon

Lars Leon is Head of Resource Sharing at the University of Kansas Libraries. He holds an MLIS from Emporia State University. His research interests include best practices, assessment, and staff development.

Nancy Kress

North Carolina State University Libraries

nancy_kress@ncsu.edu

mailing address and phone to follow

Nancy Kress is Head of Access and Delivery Services at North Carolina State University Libraries. She holds an MLIS from University of Illinois, and a Process Management and Improvement Certificate from The University of Chicago Graham School. She has practical experience applying Lean and business process improvement methods in libraries and higher education. Her research includes supply chain management and Lean principles applied to library operations, and middle management.

Title: Looking at Resource Sharing Costs

\footnotetext{
Abstract

Purpose - This paper is the result of a small cost study of resource sharing services in 23 North American libraries. Trends that have affected resource sharing costs since the last comprehensive study are discussed.

Design/methodology approach - Selected libraries were approached for this phase of study. A pilot phase helped to clarify the cost and service definitions while revising the database which served as the data collection instrument.

Findings - Immediate access to electronic items at point of use has resulted in user demand for faster turnaround for physical materials. This in turn has led to increased costs for ILL technology and shipping. Costs have decreased but continue to show a noticeable disparity between higher ILL Borrowing mean costs compared to ILL Lending. The data also clearly supports the perception that patron initiated Circ to Circ module transactions are lower than ILL. Originality/value - Libraries have been using cost data that is almost ten years old. While this study is small, the data provides an updated benchmark to assist libraries in making effective decisions regarding resource sharing. The study illustrates a range of costs which reinforce the need for libraries to investigate their own average costs for optimal decisions.
} 


\section{Introduction}

The economic crisis of the past few years means that all areas of libraries, including interlibrary loan, have to do more with less. Concurrently, the Web has changed how users interact with the library and with information. Users expect interlibrary loan (ILL) performance to match the ease and speed of electronic access. The emerging standard for delivery turnaround of articles and book chapters is within 48 hours of when the user places a request (Sturr and Parry, 2010). Services are changing as well. The prevalence of electronic journals, combined with migration of print to off-site storage and the high cost of photocopying have led many institutions to offer local document delivery. Most absorb the costs of retrieving, scanning and electronically delivering print journal content to address what users consider a time-consuming impediment to research.

Changes in the scholarly and technical environment have affected the costs of resource sharing. An unavoidable response to shrinking library budgets is to reduce acquisitions. The rising costs of journal subscriptions is causing some institutions to move away from Big Deals, using an alternative model of purchasing essential journals on a title by title basis, making use of interlibrary loan to fill the gaps (Howard, 2011). While this may save acquisition monies, some journals have a high copyright fee per use and these costs can add up quickly (Reighart and Oberlander, 2008). Monographs are also affected. Electronic books do not follow the same models as physical books; many ebook lending systems allow only one patron to access a book at a time, and lending permissions are limited (Vigen and Paulson, 2003). Thus, libraries continue to ship physical materials, in some cases using expensive expedited methods to meet consortia expectations for turnaround. Technology has benefited interlibrary loan by automating many processes that were once manual. The development of ILL management systems, electronic delivery software, and professional scanners improve the efficiency of ILL, but can be prohibitively expensive (Hosburgh and Okamoto, 2010).

Mary Jackson completed an ILL cost study for the Association of Research Libraries that libraries and vendors continue to refer to when considering new services and alternative workflows (Jackson, 2004). There has not been a comprehensive U.S. cost study since that time. New models for acquiring information resources are being developed as libraries move from a collection centric just-in-case model to a user centric just-in-time model. Selection of material is increasingly driven by the user as purchase on demand models become part of collection development. To make more effective decisions an updated view of the costs for resource sharing services is needed. This information is vital to make more informed, data-assisted decisions that are most cost-effective for the library.

\section{Literature review}

ILL is an important resource for users, providing support for research and academic course work (McCaslin, 2010). In his article on the expectations of ILL in an economic crisis, he points out that patron needs do not decrease along with the financial situations of their institutions. In fact, in an era in which collection budgets - and hence local collections are shrinking, ILL requests continue to increase. Two recent surveys of ILL conducted by Primary Research Group questioned participants on the total percentage in increase or decrease of ILL over the past three years, reporting a median increase of $9.5 \%$ to 14 (Primary Research Group, 2009, 2011). The ARL study from 2004 found an increase in borrowing (mean 75 percent) and lending (mean 59 
percent) requests from 44 libraries that had participated in the 1996 and 2002 studies (Jackson, 2004). These changes emphasize the need to know the current costs of performing ILL.

The recent literature on change in interlibrary loan includes discussion of changes in user preferences and behaviors, as well as how technology has changed ILL work and the definition of resource sharing. An OCLC report analyzing several user behavior studies conducted in the US and the UK found that the electronic environment led to clear changes in what is important to users. The study notes some common conclusions about changed user behavior, including the importance of speed and convenience, and preference for desktop access to scholarly content (OCLC Research, 2010). McHone-Chase (McHone-Chase, 2010) presents a historical perspective through a review of literature from 1995 to 2009, on how technology has changed user expectations and driven change in interlibrary loan. She found ILL has been extensively affected by technology and is struggling to keep up with user expectations for service. ILL workloads are increasing due to a combination of libraries purchasing less content, and users' ability to find more content through databases.

The evolution of resource sharing continues to change the costs of interlibrary loan. Dannelly (Dannelly, 1995) writes about the effect of the electronic era on resource sharing, beginning with the acceptance of interlibrary loan during the 1990s as a substitute for ownership. Dannelly points out there is no such thing as free information. The combined effects of technology and economic factors caused increases for interlibrary loan costs, necessitating decreases to other library services and personnel. While technology costs have dropped, reliance on electronic access has meant an increase for staff, software and workstations which have all increased the cost of ILL. The introduction of Total Quality Management (TQM) into the academic environment in the early 1990s influenced many libraries to reengineer ILL to reduce costs. Chang and Davis (Chang and Davis, 2010) examine how these changes have affected access services, including interlibrary loan. An increase in serial inflation rates meant increases in ILL transactions, causing many libraries to look at the labor-intensive process of ILL. The authors note "in short, the adoption of automated systems for circulation functions and TQM in ILL produced the first transformation wave for access services in the 1990s" (Chang and Davis, 2010).

New technologies affecting discovery and delivery of information have shifted the focus of interlibrary loan from simply delivering materials to providing user-centered service. Posner (Posner, 2007) examines what Google and other web-based information services have meant for resource sharing. One role of the library is to provide information at no cost to the patron, in a world in which all people can't afford computers or connections. This cost is often born by the library. In spite of all of the free information, there are sources for which interlibrary loan is the only option, and the introduction of document delivery service, which is labor intensive, has driven up costs. Posner discuss the possibility of putting the cost on users, but cautions that librarians should carefully consider whether it would generate enormous bills for patrons and become more of a headache and public relations challenge than a benefit for otherwise positively received ILL departments. Buchanan (Buchanan, 2009) describes how new ways to obtain information resources have forced staff to rethink the work of ILL. Discovery tools increase the ability for users to find, and request content from a myriad of sources. New tools built into the ILL request process create very different workflows, including options for purchase of content if the price is right. As the line between ILL and acquisitions continues to blur, understanding the cost differences of purchasing or borrowing content becomes increasingly important. 
As interlibrary loan became accepted as a substitute for ownership, it became necessary to understand the costs to inform decisions on whether to buy or borrow research materials. The studies in this literature review use different methodologies and report costs differently, so it is important to understand what exactly is being include and measured before comparing costs. The most recent comprehensive cost study (Jackson, 2004) collected data on the 2001-02 performance of primarily ARL libraries and assessed mediated and user-initiated borrowing and lending, as well as data from a subset of participants on local document delivery services. The study reported an average cost of a filled request for borrowing at $\$ 18.35$, and $\$ 9.48$ for lending (Jackson, 2003). The study methodology involved detailed cost worksheets; participants received an electronic report with summary data.

The National Resource Sharing Working Group for Australian (National Library of Australia, 2001) performed a large comprehensive study of interlibrary loan and document delivery by studies that would allow institutions to benchmark their operations against a set of data. The survey instrument was based on the ARL study, and in addition to costs, determined characteristics of high performing operations. The study measured filled requests, and locally filled requests were not included. The average total cost for the participating libraries was $\$ 32.10$ for borrowing, and \$17.03 for lending. Staff made up the highest proportion of total unit cost, representing 61.2 percent for borrowing and 76.8 percent for lending, with delivery being the second largest cost. On average, patrons paid \$10.28 per item. Patrons who had not paid a fee were surveyed and asked to estimate the amount they would pay. The most common response was $\$ 0$, with the average amount being $\$ 4.09$. The study found that generally, fees didn't recover costs. One library in the study had a fixed cost for the user of 8 francs per request, and the study found this covered the cost of simple requests, but that more complicated requests were found to cost on average 10.71 francs.

1n 1994 three universities at the State University of New York performed a study assessing the cost per use of a journal article as compared to the cost to borrow the item via interlibrary loan (Kingma, 1996). The study updated the data collection form used in the 1993 ARL/RLG report. To arrive at an exact cost per transaction, ILL staff members were times to determine the actual costs of processing a typical borrowing and lending request. This differs from the ARL studies, in that only the staff time employed processing the article was considered, rather than the total percentage of time a staff person worked in an ILL unit. Thus, the study did not include time that an employee was employed in an ILL unit, but not processing requests. The study found that there was a decline in average cost per transaction as requests increased.

Wichita State University in Wichita Kansas (Naylor, 1997) performed a cost study to determine the cost effectiveness of ILL as compared to commercial document delivery and purchasing full-text databases. The author also wanted to compare their institution's costs as a medium sized academic library to those from the ARL study, which are primarily large research libraries. Using data collected in fiscal year 1995/1996, the study methodology used the basic structure of the ARL/ RLG study. Personnel were found to be the highest expense, with network and communication costs second followed by delivery costs third. The cost of both filled and unfilled transactions was determined. Cost per filled borrowing transaction totaled $\$ 8.51$, while an unfilled request, as it still involved staff time, cost $\$ 4.68$ per transaction. A filled lending request cost $\$ 2.47$ and an unfilled request $\$ 1.36$. The low cost of lending for this institution results from student assistants performing the majority of work in the lending unit.

Zhou (Zhou, 1999), in an article that looks at ILL cost studies recommended that future interlibrary loan cost studies include marginal costs, specifically copyright fees. The author notes 
that in studies up to June of 1998, copyright was not included and calculated on average cost per transaction. While the Commission on New Technological Uses of Copyrighted Works (CONTU) allows five articles from one title to be copied within the calendar year, the article points to a study from 1997 that found median copyright fees for all subjects to be $\$ 5.00$. This marginal cost significantly increases the total cost per transaction. For this reason, Zhou recommends including copyright cost in any future studies.

As resource sharing continues to evolve, the variables that affect cost and what libraries will need to know to make the most efficient decisions for both users and the library will change. Reighart and Oberlander (Reighart and Oberlander, 2008) explore the future of ILL using a framework that places resource sharing into four domains: borrowing from other libraries, purchasing items from publishers, renting, and free. The convergence of acquisitions, patrondriven purchasing, collection development and new technologies will continue to push the evolution of interlibrary loan. In this new environment, libraries must evaluate the factors of reliability and stability, user expectations, cost and license terms, then determine whether to change workflow or not. The authors look at the impact of copyright, providing an example of a special issue, in which seven articles from the same issue would have had a $\$ 38.00$ copyright fee per article.

Although increasing amounts of materials appear in electronic form, users and libraries will have to deal with paper holdings for some time into the future. Pederson (Pederson, 2010) calls the separation between immediate electronic access for e-journals and print journal collections the "paper divide." To meet users preference for downloading content immediately on his/her PC some libraries are offering free document delivery to users. Providing documents from the paper collection comes at a substantial cost to libraries and includes equipment, software and staff costs. To evaluate the best option for both user and libraries, quantifiable measures of usage and cost are needed. Costs per use of both electronic serials and interlibrary loan need to be evaluated side by side. "Data concerning journal article access on both the left and right sides of the ACC (Article Access Continuum) will be invaluable for the future development of academic libraries."

Cost studies can serve as more than a benchmark for institutions to compare themselves. The data can point to ways in which an individual intuition can create efficiencies and cost savings. Cost studies have found staffing to be the most substantial portion of ILL costs. Morris (Morris, 2004) notes that labor costs can represent about $80 \%$ of total ILL cost. As a step towards reducing these she suggests rethinking the level of staff that handles transactions, comparing the salary differences between a librarian, a clerk, and a student. She provides the example of how an interlibrary loan librarian who makes $\$ 40,000$ a year can add as much as $\$ 4.00$ to each transaction.

\section{Cost Study Objectives}

The interlibrary loan community has a need for updated cost data, as the landscape of resource sharing has changed dramatically since the last comprehensive study which is almost ten years old. In an environment of multiple formats, increase in user requests for journal content and rising subscription prices, there is a need for current cost data to inform service and collection development decisions. Past resource sharing studies have primarily examined turnaround time, fill rate and unit cost for successfully filled requests. Deciding what resource sharing activities and which costs were collected was determined by the authors, after discussion with pilot library participants. The authors were initially prompted to undertake a cost study due to a need for up to 
date costs to make decisions regarding purchasing over borrowing, as well as format decisions and full journal subscription access vs. pay per article. Thus this study focuses on unit costs alone. Since the last study libraries are increasingly providing locally held and accessible items via interlibrary loan and other library units, hence the study measures unit cost for delivery of locally held and accessible items. Finally, we decided to include both filled and unfilled requests, as costs are incurred to process all requests, and staffing represents the highest unit cost for ILL operations.

The goal for this study was to create a prototype costing tool that was:

- Simple to use, relying on electronic data entry and not paper forms.

- Required minimum broad data elements to enable comparison between institutions but also the ability to break down certain categories into granular costs.

This paper is a study of 23 primarily medium to large academic libraries. The results of this small study will provide average costs that libraries can consider using and form the basis for contributing to a larger study with more libraries that should provide a more effective wider use of data such as by library type.

\section{Research Data Design and Collection}

\section{Data Design}

We defined the data to collect after reviewing the literature and determining what was most relevant for current decision making. We identified resource sharing services as services. We selected the fiscal year that runs July 1, 2010 through June 2011 so we could have complete and comparable data between libraries. We developed a Microsoft Access ${ }^{\circledR}$ database that each participating library would use as the collection tool. The costs included in this study were staffing, equipment, copyright, payments to supplying libraries or other sources, payments received for requests fulfilled, management tools (e.g. ILLiad), request systems (e.g. OCLC, RAPID), shipping costs, and supplies. See the appendix for the definitions.

The resource sharing service costs were separated out as the following services. See the appendix for definitions.

Borrow through Circ to Circ module

Copies from local collections to local patrons

ILL Borrowing Copies

ILL Borrowing Loans

ILL Lending Copies

ILL Lending Loans

Lend through Circ to Circ module

Deliver to Campus

Mail to non-Campus

Page from local collections to local patrons

For each service, fiscal year request totals were collected for all ILL requests submitted. Eight categories were used to calculate unit cost per service: staff, request systems, request management tools, shipping, equipment, supplies, fees (debits and credits), and copyright. For 
the purpose of analysis, we used the costs applied over all requests submitted both filled and unfilled.

\section{Participating Libraries}

We completed a pilot data collection with five libraries in order to determine the best data definitions, revise instructions, and modify the Access ${ }^{\circledR}$ database. As our goal was to develop a prototype costing tool, we limited the number of libraries invited to participate, soliciting participation from a limited number of libraries through selected consortiums. Almost all participating libraries were medium to large academic libraries. A list of the pilot and full phase participating libraries can be found in the appendix. We analyzed the final data received and were able to keep almost all submitted data for the final analysis. However, in a few cases we excluded some data where it was extremely less or more expensive than the norm.

\section{Data Collection}

A website was created that included the Microsoft Access ${ }^{\circledR}$ database to download, cost gathering guidelines and online tutorials, and information on participation and privacy. Participants were able to enter data into their own copy of the study database. The database structure made it easy for participants to extract the information needed for the cost study. In some cases, data such as staff salaries cannot be publicly shared. This method of data collection allowed those libraries to enter their own staff salaries and only send the aggregated data that was needed for the study. Once they completed entering data, participants were able to see their unit costs immediately.

\section{Reports generated}

Once each participant completed entering data into their copy of the database they were then able to immediately download reports specific to their library. One report was based on the total requests submitted for each service while the other two provided data across filled requests as defined in two ways. Each report provided the mean cost by category for each service entered by that library. One filled request report did not count ILL Borrowing copy requests that were returned to the patron as locally available in licensed content. The other filled request report did. 


\section{Results of study and analysis}

Table 1 displays the mean costs across all requests submitted. As stated earlier, the data set is small; especially for some of the services. However, the authors feel this information helps identify areas that need further exploration.

Table 1

\begin{tabular}{|c|c|c|c|c|c|c|c|c|c|c|c|c|c|}
\hline Service & $\begin{array}{l}\mathrm{Nr} \\
\text { Libs. }\end{array}$ & $\begin{array}{l}\text { Mean } \\
\text { Nr. } \\
\text { Reqs }\end{array}$ & $\begin{array}{l}\text { Mean } \\
\text { Total } \\
\text { Costs }\end{array}$ & $\begin{array}{l}\text { Credits } \\
\text { pd. to } \\
\text { the } \\
\text { Libs }\end{array}$ & $\begin{array}{l}\text { Net } \\
\text { Mean }\end{array}$ & Staff & Equip & Cpyrt & Debits & $\begin{array}{l}\text { Mgmt } \\
\text { Tools }\end{array}$ & $\begin{array}{l}\text { Req } \\
\text { Sys }\end{array}$ & Shipp. & Suppl \\
\hline $\begin{array}{l}\text { Borrow through Circ to } \\
\text { Circ module }\end{array}$ & 5 & 27,442 & $\$ 3.85$ & $\$ 0.00$ & $\$ 3.85$ & $\$ 2.18$ & $\$ 0.18$ & $\$ 0.00$ & $\$ 0.00$ & $\$ 0.02$ & $\$ 0.19$ & $\$ 1.27$ & $\$ 0.00$ \\
\hline $\begin{array}{l}\text { Lend through Circ to } \\
\text { Circ module }\end{array}$ & 5 & 28,105 & $\$ 4.70$ & $\$ 0.00$ & $\$ 4.70$ & $\$ 2.68$ & $\$ 0.24$ & $\$ 0.00$ & $\$ 0.00$ & $\$ 0.02$ & $\$ 0.21$ & $\$ 1.53$ & $\$ 0.01$ \\
\hline ILL Borrowing Copies & 18 & 20,391 & $\$ 7.98$ & $\$ 0.05$ & $\$ 7.93$ & $\$ 4.33$ & $\$ 0.05$ & $\$ 0.81$ & $\$ 1.94$ & $\$ 0.12$ & $\$ 0.71$ & $\$ 0.00$ & $\$ 0.02$ \\
\hline ILL Borrowing Loans & 17 & 13,875 & $\$ 12.12$ & $\$ 0.01$ & $\$ 12.11$ & $\$ 6.86$ & $\$ 0.12$ & $\$ 0.00$ & $\$ 1.93$ & $\$ 0.14$ & $\$ 0.61$ & $\$ 2.31$ & $\$ 0.14$ \\
\hline ILL Lending Copies & 18 & 28,232 & $\$ 4.11$ & $\$ 1.09$ & $\$ 3.02$ & $\$ 2.90$ & $\$ 0.24$ & $\$ 0.00$ & $\$ 0.00$ & $\$ 0.16$ & $\$ 0.79$ & $\$ 0.00$ & $\$ 0.03$ \\
\hline ILL Lending Loans & 18 & 20,210 & $\$ 6.21$ & $\$ 1.00$ & $\$ 5.21$ & $\$ 3.28$ & $\$ 0.07$ & $\$ 0.00$ & $\$ 0.04$ & $\$ 0.16$ & $\$ 0.74$ & $\$ 1.86$ & $\$ 0.06$ \\
\hline $\begin{array}{l}\text { Copies from Local } \\
\text { Collections to Local } \\
\text { Patrons }\end{array}$ & 14 & 10,933 & $\$ 7.14$ & $\$ 0.00$ & $\$ 7.14$ & $\$ 6.43$ & $\$ 0.48$ & $\$ 0.00$ & $\$ 0.00$ & $\$ 0.11$ & $\$ 0.08$ & $\$ 0.00$ & $\$ 0.04$ \\
\hline $\begin{array}{l}\text { Page from Local } \\
\text { Collections to Local } \\
\text { Patrons }\end{array}$ & 9 & 18,468 & $\$ 7.34$ & $\$ 0.00$ & $\$ 7.34$ & $\$ 6.13$ & $\$ 0.17$ & $\$ 0.00$ & $\$ 0.00$ & $\$ 0.04$ & $\$ 0.00$ & $\$ 0.92$ & $\$ 0.09$ \\
\hline Deliver to Campus & 3 & 13,805 & $\$ 3.65$ & $\$ 0.00$ & $\$ 3.65$ & $\$ 3.48$ & $\$ 0.02$ & $\$ 0.00$ & $\$ 0.00$ & $\$ 0.01$ & $\$ 0.00$ & $\$ 0.00$ & $\$ 0.14$ \\
\hline Mail to Non-Campus & 2 & 1,221 & $\$ 7.54$ & $\$ 0.00$ & $\$ 7.54$ & $\$ 5.50$ & $\$ 0.06$ & $\$ 0.00$ & $\$ 0.00$ & $\$ 0.03$ & $\$ 0.00$ & $\$ 1.89$ & $\$ 0.06$ \\
\hline
\end{tabular}


Table 2 illustrates the mean and median costs for the total net cost and the staff only costs. Some services median and mean costs are close. There were some libraries more distant from the mean but there was a good distribution. However, for some services the median is noticeably lower. This illustrates that some libraries with higher costs may be increasing the overall average greater than the average cost. These numbers are a good start for analysis but a follow-up study should have a larger participant pool to help determine if the averages are useful for a greater number of libraries.

Table 2 Average costs based on all requests submitted

\begin{tabular}{|c|c|c|c|c|c|c|}
\hline \multirow[b]{2}{*}{ Service } & \multirow[b]{2}{*}{$\begin{array}{c}\mathrm{Nr} \\
\text { Libs. }\end{array}$} & \multirow{2}{*}{$\begin{array}{l}\text { Mean } \\
\text { Reqs. } \\
\text { total }\end{array}$} & \multicolumn{2}{|c|}{ Net Total Costs } & \multicolumn{2}{|c|}{ Staff only } \\
\hline & & & Mean & Median & Mean & Median \\
\hline Borrow through Circ to Circ module & 5 & 27,442 & $\$ 3.85$ & $\$ 2.94$ & $\$ 2.22$ & $\$ 1.35$ \\
\hline Lend through Circ to Circ module & 5 & 28,105 & $\$ 4.70$ & $\$ 3.58$ & $\$ 2.68$ & $\$ 1.97$ \\
\hline ILL Borrowing Copies & 18 & 20,391 & $\$ 7.93$ & $\$ 7.68$ & $\$ 4.33$ & $\$ 2.85$ \\
\hline ILL Borrowing Loans & 17 & 13,875 & $\$ 12.11$ & $\$ 12.02$ & $\$ 6.86$ & $\$ 6.98$ \\
\hline ILL Lending Copies & 18 & 28,232 & $\$ 3.02$ & $\$ 2.54$ & $\$ 2.90$ & $\$ 2.59$ \\
\hline ILL Lending Loans & 18 & 20,210 & $\$ 5.21$ & $\$ 4.73$ & $\$ 3.28$ & $\$ 3.09$ \\
\hline Copies from Local Collections to Local Patrons & 14 & 10,933 & $\$ 7.14$ & $\$ 5.94$ & $\$ 6.43$ & $\$ 5.34$ \\
\hline Page from Local Collections to Local Patrons (1) & 9 & 18,468 & $\$ 7.34$ & $\$ 4.02$ & $\$ 6.13$ & $\$ 3.88$ \\
\hline Deliver to Campus & 3 & 13,805 & $\$ 3.65$ & $\$ 3.02$ & $\$ 3.48$ & $\$ 2.88$ \\
\hline Mail to Non-Campus & 2 & 1,221 & $\$ 7.54$ & $\$ 7.54$ & $\$ 5.50$ & $\$ 5.50$ \\
\hline
\end{tabular}

(1) One library had 108,015 requests. Excluding this data brings the average to 7,275.

\section{Observations on Data}

\section{General Overview}

Staffing continues to be the largest cost in all categories. The debits and shipping costs are the next highest average costs and warrant some analysis. However, this data confirms the importance of managing staff costs as the most important factor. This study did not separate out mediated and unmediated requests for interlibrary loan. That should be accomplished in a further study. The framework of the study though did help illustrate the impact on costs that a library can have when they are able to minimize staff time such as in the Circ to Circ module type services. In addition, several libraries in the study had lower costs than the average. Further analysis is needed to understand what systems, workflows, policies and other factors have helped to reduce their costs. 


\section{Comparing Circ to Circ module system Costs and Interlibrary Loan Costs}

This study provides additional evidence on how much less expensive the Circ to Circ systems are compared to traditional interlibrary loan. This study shows a net average cost per request of $\$ 3.85$ to borrow in a Circ to Circ module compared to $\$ 12.11$ to borrow loans via traditional interlibrary loan. Two critical areas impact these figures. The main area is staffing where Circ to Circ Borrowing average $\$ 2.22$ while ILL Borrowing loans is $\$ 6.86$. A more detailed analysis is needed of staffing in the other services to determine how to make equivalent progress as Circ to Circ modules.

Figure1: Average cost across all requests for services where obtain materials from other libraries and sources

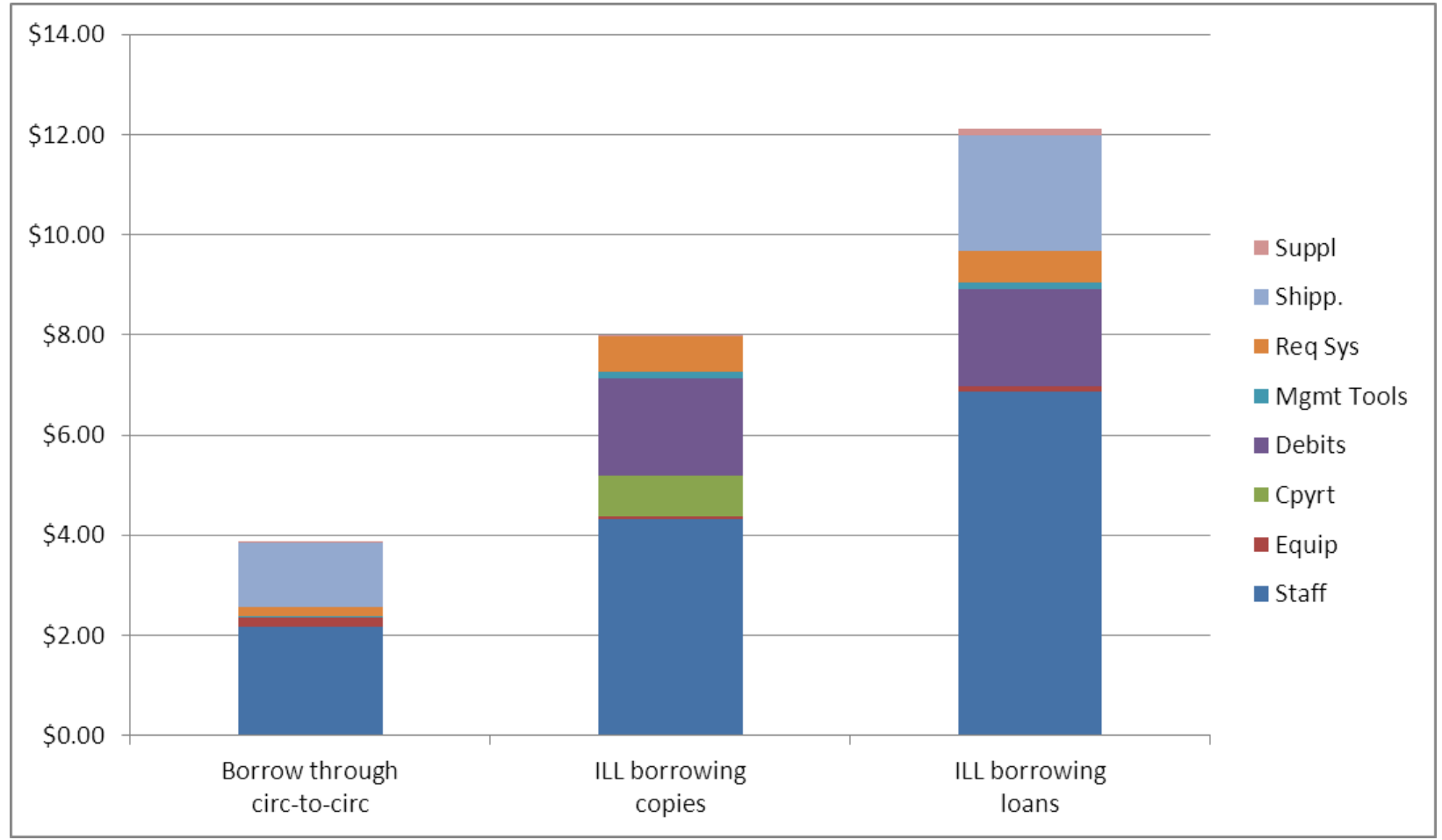

\section{Shipping costs}

For services that involved moving physical materials the next highest cost area was typically shipping. For ILL Borrowing Loans this was 19\% of the net mean cost per request. For Circ to Circ module borrowing and lending this was around 32 to $33 \%$ of the net mean cost per request. Reducing staffing costs will help. Several libraries had lower mean costs. Further study is needed of their workflows and commitments to determine applicability for the greater ILL community.

\section{Comparing Costs: Leon/Kress and ARL 2004}

The literature review discussed recent factors that have changed the nature of resource sharing. This raises questions regarding how costs have changed in the almost ten years since the ARL study. Our study defined, collected and measured the data differently, so the numbers cannot be compared directly but some observations can be made. Tables $3 \& 4$ compare our data with the 2002 ARL (Jackson, 2004) data. Observations and discussion of major points follows. 
Table 3: Borrowing Costs by Category (ILL Borrowing Copies and ILL Borrowing Loans)

\begin{tabular}{|l|c|l|c|c|}
\hline \multicolumn{2}{|c|}{ ARL (2002 data) } & \multicolumn{3}{c|}{ Leon/Kress (FY 2011 data) } \\
\hline Cost Category & $\begin{array}{c}\text { Percentage } \\
\text { of Unit Cost }\end{array}$ & Cost Category & $\begin{array}{c}\text { Percentage of } \\
\text { Unit Cost }\end{array}$ & $\begin{array}{c}\text { Percentage of Unit } \\
\text { Cost (excluding } \\
\text { Debits) }\end{array}$ \\
\hline Staff & $58 \%$ & Staff & $55 \%$ & $70 \%$ \\
\hline Network & $1 \%$ & $\begin{array}{l}\text { Request } \\
\text { systems }\end{array}$ & $7 \%$ & $9 \%$ \\
\hline Delivery & $5 \%$ & $\begin{array}{l}\text { Request mgmt } \\
\text { tools }\end{array}$ & $1 \%$ & $2 \%$ \\
\hline Photocopy & $0 \%$ & Shipping & $8 \%$ & $9 \%$ \\
\hline Supplies & $1 \%$ & Supplies & $1 \%$ & $1 \%$ \\
\hline Equipment & $2 \%$ & Equipment & $1 \%$ & $8 \%$ \\
\hline Borrowing Fees & $20 \%$ & Copyright & $6 \%$ & -- \\
\hline & & Debits & $21 \%$ & $\$ 7.69$ \\
\hline $\begin{array}{l}\text { Mean Mediated } \\
\text { Cost }\end{array}$ & $\$ 17.50$ & Mean Cost & $\$ 9.62$ & \\
\hline
\end{tabular}

Table 4: Lending Costs by Category (ILL Lending Copies and ILL Lending Loans)

\begin{tabular}{|l|c|l|c|}
\hline \multicolumn{2}{|c|}{ ARL (2002 data) } & \multicolumn{2}{c|}{ Leon/Kress (FY 2011 data) } \\
\hline Cost Category & $\begin{array}{c}\text { Percentage of Unit } \\
\text { Cost }\end{array}$ & \multicolumn{1}{|c|}{$\begin{array}{c}\text { Cost Category } \\
\text { Cost }\end{array}$} & $\begin{array}{c}\text { Percentage of Unit } \\
\text { Staff }\end{array}$ \\
\hline Network & $5 \%$ & Staff & $63 \%$ \\
\hline Delivery & $13 \%$ & Request systems & $16 \%$ \\
\hline Photocopy & $2 \%$ & Request mgmt tools & $3 \%$ \\
\hline Supplies & $1 \%$ & Shipping & $12 \%$ \\
\hline Equipment & $4 \%$ & Supplies & $1 \%$ \\
\hline & & & $4 \%$ \\
\hline Mean Mediated Cost & $\$ 9.27$ & Mean Net Cost & $\$ 3.93$ \\
\hline
\end{tabular}

The first point to note is that the ARL data counts filled requests, whereas our data counts all requests, both filled and unfilled. The ARL study excludes RAPID from mediated categories; our study includes RAPID and other user-initiated services. The Circ to Circ, Deliver to Campus and Mail to Campus services were excluded from the Leon/Kress data for this comparison to provide similar data. Comparing the 2002 and 2011 data raises many questions, particularly why staffing represents similar percentages of total unit costs for both studies in ILL Borrowing. Most of these cannot be answered and are not addressed in this article, but point to future areas for research. There are a few trends however that have affected unit costs which we can comment on. 
The Leon/Kress "Shipping" cost category is similar to the ARL "Delivery" cost category. This category has doubled for borrowing while being similar for lending. To meet user service desires for fast delivery, many libraries in this study have been using expedited shipping for returnables and moving away from slower ground mail. Several libraries participating in the study have consortia turnaround time requirements for both electronic and physical materials. Further analysis is needed as to the discrepancies for the percentage changes between borrowing and lending.

The other increase worth noting concerns network and system costs. The ARL "Network" costs included "applicable telephone, Ariel or other electronic transmission, electronic mail, Internet, and network fees (OCLC, RLIN, etc)" (Jackson, 2004). Leon/Kress "Request systems" included OCLC, RAPID, Article Reach, LINK+. We did not include phone, email and Internet. This increase is due to increases in OCLC fees in the time since the ARL study, and that at present, libraries may belong to several fee based resource sharing systems.

\section{Conclusions and next steps}

The purpose of this study was to provide some updated average costs to assist libraries in making decisions in the increasingly complex environment of expanded resource sharing services and buy versus borrow decisions. These challenges have arisen even as patrons increasingly demand faster service. In addition, this was a test of a stand-alone Microsoft Access ${ }^{\circledR}$ database that empowered libraries to enter their own data and immediately see their own average costs.

The primary conclusion is that this information illustrated that costs have changed and libraries need to determine their own, updated costs to make the most accurate decisions. Use of a tool like the database provided empowered libraries to gather and determine their own costs. With this information, each library is able to make more informed decisions. In addition, their contribution of this type of data in an organized fashion to this study has helped to provide greater insight into costs amongst different libraries. This is useful for the library community. The figures in this study could be a starting point for libraries to consider but the authors encourage libraries to determine their own costs through our tool or future group efforts.

The largest cost across resource sharing services continues to be staffing. Additional more granular analysis is needed especially in the ILL Borrowing services. Most participants in this study had a combination of unmediated and mediated requests in these services. The combination of mediated and unmediated requests helps provide useful averages to help with buy versus borrow decisions but does not give practitioners enough detail to understand the most cost effective means within ILL of obtaining materials. Further analysis is needed specifically into why staff costs are high and which workflows provide the best return for the services desired.

The authors hope this information encourages libraries to take the time to identify their own costs and to contribute to a community effort. The ILL community has a tremendous track record of sharing. Extending that cooperation into a broad, shared look at costs across libraries can only enhance our common understanding that should lead to efficiencies and better decisions as we expand services and collaborate more with other library services such as acquisitions and collection development. 


\section{References}

Buchanan, S. (2009), "Interlibrary loan is the new reference: reducing barriers, providing access and refining services", Interlending and Document Supply, Vol. 37, No. 4, pp. 168-170.

Chang, A. and Davis, D. (2010), "Transformation of Access Services in the new era", Journal of Access Services, Vol. 7, pp. 109-120.

Dannelly, G. (1995), "Resource sharing in the electronic era: potentials and paradoxes", Library Trends, Vol. 43, No. 4, pp. 663-678.

Hosburgh, N. and Okamoto, K. (2010), "Electronic document delivery: a survey of the landscape", Journal of Interlibrary Loan, Document Delivery and Electronic Reserve, Vol. 20, No. 4, pp. 233-252.

Howard, J. (2011), 'Libraries abandon expensive 'Big Deal' subscription packages to multiple journals", Chronicle of Higher Education, July 17, available at: http://chronicle.com/article/Libraries-Abandon-Expensive/128220/

Jackson, M. (October/December 2003), “Assessing ILL/DD services study: initial observations”, ARL Bimonthly Report 230/231.

Jackson, M. (2004), Assessing ILL/DD services: new cost-effective alternatives, Association of Research Libraries, Washington, DC.

Kingma, B. 1996, The economics of access versus ownership, Hawthorne Press, NY.

McCaslin, D. (2010), "What are the expectations of interlibrary loan and electronic reserves during an economic crisis", Journal of Interlibrary Loan, Document Delivery and Electronic Reserve, Vol. 20, No. 4, pp. 227-231.

McHone-Chase, S. (2010), "Examining change within interlibrary loan", Journal of Interlibrary Loan, Document Delivery and Electronic Reserve, Vol. 20, pp. 201-206.

Morris, L. (2004), "How to lower your interlibrary loan and document delivery costs: an editorial", Journal of Interlibrary Loan, Document Delivery and Information Supply, Vol. 14, No. 4, pp. 2-3.

National Resource Sharing Working Group 2001, Interlibrary loan and document delivery benchmarking study, National Library of Australia.

Naylor, T. (1997), "The cost of interlibrary loan services in a medium-sized academic library", Journal of Interlibrary Loan, Document Delivery and Information Supply, Vol. 8, Issue 2.

OCLC Research 2010, The digital information seeker: report of the findings from selected OCLC, RIN, and JISC user behavior projects, research report prepared by L. Silipigni and T. Dickey, OCLC Research.

Pederson, W. (2010), "The paper divide", The Serials Librarian, Vol. 59, No. 3, pp. 281-301.

Posner, B. (2007), "Library resource sharing in the early age of Google", Library Philosophy and Practice, Special Issue: libraries and Google, viewed 2 August, 2011, <http://www.webpages.uidaho.edu/ mbolin/lppgoogle.htm>.

Primary Research Group 2009, Higher education interlibrary loan management benchmarks, 2009-10 edn, Primary Research Group.

Primary Research Group 2011, Academic interlibrary loan benchmarks, 2011 edn, Primary Research Group.

Reighart, R. and Oberlander, C. (2008), "Exploring the future of interlibrary loan: generalizing the experience of the University of Virginia, USA", Interlending and Document Supply, Vol. 36, No. 4, pp. 184-190. 
Sturr, N. and Parry, M. (2010), "Administrative perspectives on dynamic collections and effective interlibrary loan", Journal of Interlibrary Loan, Document Delivery \& Electronic Reserve, Vol. 20, No. 2, pp. 115-125.

Vigen, J. and Paulson, K. (2003), "E-books and interlibrary loan: an academic centric model for lending", paper presented at the 8th Interlending and Document Supply Conference, 2831 October, Canberra, available at: www.nla.gov.au/ilds/abstracts/ebooksand.htm

Zhou, J. (1999), "Interlibrary loan cost studies and copyright fees", Journal of Interlibrary Loan, Document Delivery and Information Supply, Vol. 4, No. 4, pp. 29-38. 


\section{APPENDIX}

\section{Costs included in the study}

Staffing - total salary, including fringes, for everyone that helped with the services. This included an appropriate percentage of managers' time.

Equipment - Equipment used in support of services such as scanners, faxes, multifunctional devices, and computers. Equipment costs entered were amortized over the replacement cycle of the library submitting costs or a standard study value if there was not one.

Copyright - Copyright costs paid for ILL Borrowing.

(Debits) Payments to supplying libraries or other sources - This included payments to other libraries, document suppliers, and publishers for services included in the study.

(Credits) Payments received for requests fulfilled - This included payments received by the participating library for items fulfilled to other libraries. For several libraries, this also included payments from their own patrons for items supplied to them.

Management tools - This included whatever software and supporting hardware used to manage requests. For almost all participants this was ILLiad and either software hosting fees or local hardware costs such as servers.

Request systems - This included systems that helped to share requests with other libraries. For almost all participants this included OCLC and for many RAPID. Several "Circ to Circ" modules were also linked such as LinkPlus or OrbisCascade.

Shipping costs - All costs that helped move materials to/from the participating library (e.g. USPS, UPS, Fed Ex, courier costs).

Supplies - all supplies associated with the services in the study. Rough estimates were okay due to the very small percentage of cost.

\section{Services included in the study}

Borrow through Circ to Circ module - Unmediated loan requests from participating library's patrons for loans not available locally. Patron initiates requests that are sent in unmediated fashion to the potential lending library.

Lend through Circ to Circ module - Unmediated loan requests for the participating library's collections from other libraries. Other libraries' patrons initiate requests that are sent in unmediated fashion to the participating library.

ILL Borrowing Copies - Mediated and unmediated requests for copies from other libraries and supplying sources for the participating library's local patrons. 
ILL Borrowing Loans - Mediated and unmediated requests for loans from other libraries and supplying sources for the participating library’s local patrons.

ILL Lending Copies - Copy requests from other libraries for the participating library's collections.

ILL Lending Loans - Loan requests from other libraries for the participating library's collections.

Copies from local collections to local patrons - Requests from the participating library's patrons for copies of items from the participating library's collections.

Deliver to Campus - Requests from the participating library's patrons for loans to be delivered to their local patrons' campus addresses.

Mail to non-Campus - Requests from the participating library's patrons for loans to be mailed to their local patrons' off-campus addresses.

Page from local collections to local patrons - Requests from the participating library's patrons for loans from their local collections to be paged and made available at a participating library's service desk.

\section{Participating libraries}

Arizona State University

Florida International University

Kansas State University

Massachusetts Institute of Technology

New York University

Ohio State University

Oklahoma State University

Oregon State University

Pennsylvania State University

Philadelphia Museum of Art

Texas A\&M University

University of Arizona
University of Colorado Boulder

University of Connecticut

University of Houston

University of Iowa (pilot library)

University of Kansas (pilot library)

University of Massachusetts Medical School

University of Nebraska Lincoln (pilot library)

University of Nevada Las Vegas (pilot library)

University of Utah (pilot library)

Utah State University

Washington University in St. Louis 